\title{
Simulation as a decision tool in construction process management in turbulent environment
}

\author{
Kinga Katafoni ${ }^{1, *}$, and Jerzy Paslawski ${ }^{2}$ \\ ${ }^{1}$ CTM Master Graduate Student, Poznan University of Technology \\ ${ }^{2}$ Construction Engineering and Management, Poznan University of Technology
}

\begin{abstract}
This paper is dedicated to simulation idea of construction process for decision-making aid. An aim is to improve technological decisions for concreting operation at low temperature. A risk of destruction of concrete structure is a critical problem in this situation. A sudden drop in temperature may result in disqualification of the concrete element or the entire structure. The proposed solution is based on a simulation of the process of maturing of the concrete element based on experiments in the laboratory (e.g. heat of hydration and dynamics of growth of compressive strength depending on the temperature). The case study proved that the traditional approach to the management of concreting technology (based on one 48-hour forecast) is extremely risky when operating in a turbulent and changing environment. The proposed flexible approach is based on systematically updated simulation and is more effective thanks to the possibility of activating active flexible procedures to prevent freezing of concrete in case of pessimistic scenario.
\end{abstract}

\section{Introduction}

Construction is a field of economic activity that is significantly different from the typical production activity carried out under factory conditions. The basic difference results from the implementation of construction processes under uncontrolled conditions. The influence of weather conditions is a manifestation of the impact of the dynamically changing environment. Variable climatic conditions in time and space generate different deadlines (and related costs) for the implementation of various construction processes and the related risk of failure to meet the assumed deadline for implementation, budget overrun and failure to meet quality requirements $[1,2]$. It is necessary to emphasize the oftenencountered pressure to shorten the implementation cycle, which imposes the necessity to continue the works An example of a process exposed to a significant weather risk is concreting under conditions of cold temperature, when despite the start of the process under favorable conditions there is a danger of sudden deterioration of maturation conditions (frost attack) and damage to the concrete structure at the initial stage of curing. Under these conditions, decisions regarding the adopted technology are usually made in situation of information deficit and awareness of the necessity to implement the process in an

\footnotetext{
* Corresponding author: katafoni.kinga@gmail.com
} 
environment characterized by a large range of variability, high uncertainty and high dynamics of change.

The use of a flexible approach enables sequential decision making based on gradually updated data and simulation models for launching appropriate procedures in the event of a pessimistic scenario. It gives the opportunity to continue the process implementation while ensuring the achievement of the assumed results (quality requirements) despite unfavorable weather conditions.

The purpose of this article is to show the important role that simulation plays as a tool for managing construction processes. It is important to emphasize the importance of synergy between monitoring (information on the course of the process in progress and its environment), a gradually updated forecast and simulation. This gives the basis for decision-making at individual stages of the process.

After this introduction, a problem has been defined which involves a high risk of damaging the structure of the concrete maturing at low temperature, when a sudden drop in ambient temperature can lead to irreversible changes in the concrete structure (e.g. a decrease in compressive strength by $80 \%$.). This often means that you need to demolish an item and re-execute it. Based on the authors' own experience, this may lead to an increase in costs of up to $300-400 \%$. Then, a solution based on a flexible approach was indicated.

The third part indicates the important role of simulation in the decision making process regarding the application of the active flexibility option (adaptability). The example describes the application of the proposed method in the case of concreting a gas station sealing plate at reduced temperature. The article was concluded with conclusions indicating the prospects of further research.

\section{Problem definition}

Climate condition in Poland are variable and changes in temperature have huge impact on processes on the building site. The most sensitive process to low temperature is concreting. Wrong estimation of weather condition generate a huge amount of waste and costs. Moreover it effects delays in schedule due to fact that stripping time for the concrete form work has significant influence on schedule. If the process of form work removal is performed too soon there is a possibility to destroy the construction. Furthermore, it creates a hazardous condition for workers. The Table 1 shows the dependence of variable weather condition on construction works.

Table 1. Dependence of variable weather condition on construction activities [1,2].

\begin{tabular}{|c|c|c|c|}
\hline $\begin{array}{c}\text { Construction operation/ } \\
\text { Weather condition }\end{array}$ & Earthworks & Concreting & $\begin{array}{c}\text { Assembly } \\
\text { construction }\end{array}$ \\
\hline Temperature $\leq 0^{\circ} \mathrm{C}$ & Low/Medium & High & Low \\
\hline Snow $/$ rainfall $>1 \mathrm{~mm} / \mathrm{h}$ & Low & High & High \\
\hline Wind speed $>10 \mathrm{~m} / \mathrm{s}$ & Low & Medium & High \\
\hline Visibility/fog & Medium & Low & Medium \\
\hline Ice/snow layer & Medium/High & High & High \\
\hline
\end{tabular}


Concreting at low temperature is encumber by a risk of damage in concrete structure, especially in early stage of hardening concrete. The main danger for concrete in early state is damaging of structure by freezing water. If the concrete mixture freeze over after initial setting time the water increases volume in concrete pores and destroys the bonding chain in concrete paste. It brings negative results such as lower compressive and tensile strength.

The degree of harmfulness of freezing a concrete mixture increase significantly in stage between initial setting time and end of setting time due to fact that at this curing cycle occur the hardening processes in concrete as shown Figure 1. If the concrete mixture freeze over before initial setting time the hydration process is inhibited or stopped and freeze water is not dangerous for microstructure of paste [3].

The most harmful situation for construction is when the concrete is hard and destructive processes in structure are irreparable. In that case waste of money and time are huge and are strictly connected with demolition of construction. This situation on construction site forced the project managers to analyze the case and the results often shows that prevention as well as prediction could save the construction in future.

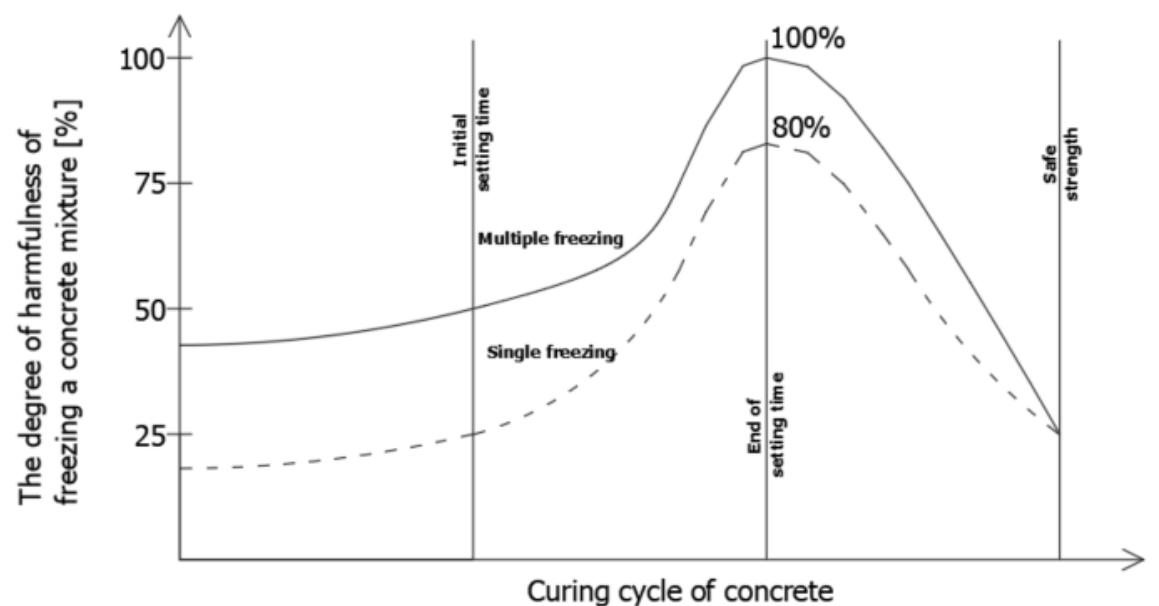

Fig. 1. The degree of harmfulness of freezing a concrete mixture. [3]

In decision making situation, when the quality and quantity of information are low and environment is strongly variable the solution is usage of flexible approach. Implementation of flexibility can be based on two main strategies. First, also called as passive flexibility, refers to action performed before negative scenario occur and is the first component of flexibility to achieve the assumed results of construction process in uncertain environment [4]. The possible actions in passive flexibility are as follow:

- Preparation of proper formula of the concrete mixture, where amount of cement, w/c ratio as well as chemical admixtures and additives are taken into account,

- Using cement with higher amount of cement clinker CEM I and CEM II and also with higher strength class such as 42.5 and 52.5 ,

- Increasing the proportion of cement by $5-10 \%$ in composition of the concrete mixture,

- Using chemical admixtures, which: allow to lowering the freezing point of water in concrete, accelerate the bonding by increasing the initial rate of reactions between cement and water as well as reduce the amount of mixing water,

- Using modern concrete modifiers like PCM (Phase Changed Material).

The second approach, active flexibility, is performed when negative scenario occur. It is a second component of flexibility based on adaptation to changing conditions, especially 
the basis of active flexibility is monitoring of condition and construction process in progress [5]. Examples of this actions in concreting process are:

- Using specially heated form work to protect the pouring concrete from low temperature,

- Using a heating concrete method when the concrete is heating up by warm air heating, low-pressure steam or electric installation,

- Using covers and foils which insulate the concrete, reducing heat losses,

- Using heating tents, which protect not only against the rain or snow but also against strong wind.

\section{Simulation as a trigger for active flexibility option}

Modern solutions used in construction process give a possibility to simulate an uncertain cases where discrete events can appear. Simulation is a tool to evaluate a performance of system, existing or proposed, under different configurations of interest and over long periods of real time [6].

Application of simulation in construction process management proceed from limitation of other method such as mathematical programming or queuing theory [7]. The first researcher who proposed usage of simulation in construction equipment choosing was Teicholz in 1963. Ten years later in 1973 Halpin introduced the concept of simulation, bases on cyclic process model. From now the dynamic development of CYCLONE purpose is dated to make an efficient decisions to manage the production systems in construction industry based on simulation. This development process exists to date and some examples of modern software are described at the Table 2.

Table 2. The examples of simulation software and basic features of software [8-12].

\begin{tabular}{|c|c|}
\hline Simulation Software & Basic features of software \\
\hline MicroCyclone & $\begin{array}{l}\text { - Fundamental software for Construction } \\
\text { Process Simulation } \\
\text { - The operations are reduced to simple } \\
\text { flowchart what allow to studying the } \\
\text { interaction easily }\end{array}$ \\
\hline AnyLogic & $\begin{array}{l}\text { - Allow to visualize the process in } 2 \mathrm{D} / 3 \mathrm{D} \\
\text { - Different goals of participating could be } \\
\text { taken into consideration }\end{array}$ \\
\hline VR simulation & $\begin{array}{l}\text { - Integrate the MS Access Database, } \\
\text { AutoCAD drawings and MS Project } \\
\text { Schedules }\end{array}$ \\
\hline Stroboscope & $\begin{array}{l}\text { - Is based on three-phase activity } \\
\text { scanning } \\
\text { - Using of graphical network-based } \\
\text { representation }\end{array}$ \\
\hline SDESA & $\begin{array}{l}\text { - Results from the recent construction } \\
\text { engineers research } \\
\text { - Allow the spatial definition of a } \\
\text { construction system in 3D }\end{array}$ \\
\hline
\end{tabular}


According to literature the simulation consists of two groups continuous and DiscreteEvent Simulation. The difference between continuous simulation and DES is that the first provides the changes in system continuously over time and the second approach assumes the system changes instantaneously. The main aim of Discrete-Events Simulation (DES) is to provide a sufficient solution to modelling processes on building site. Due to simulation of real events engineers can estimate and reduce a time of processes or waste of material and provide security for construction and workers [13].

To make clear an idea of usage a simulation in construction process the further disquisition will be based on concreting in low temperature. Decision making during concreting process, depending on weather condition and weather forecast. Figure 2 presents a role of simulation in concreting process in low temperature.

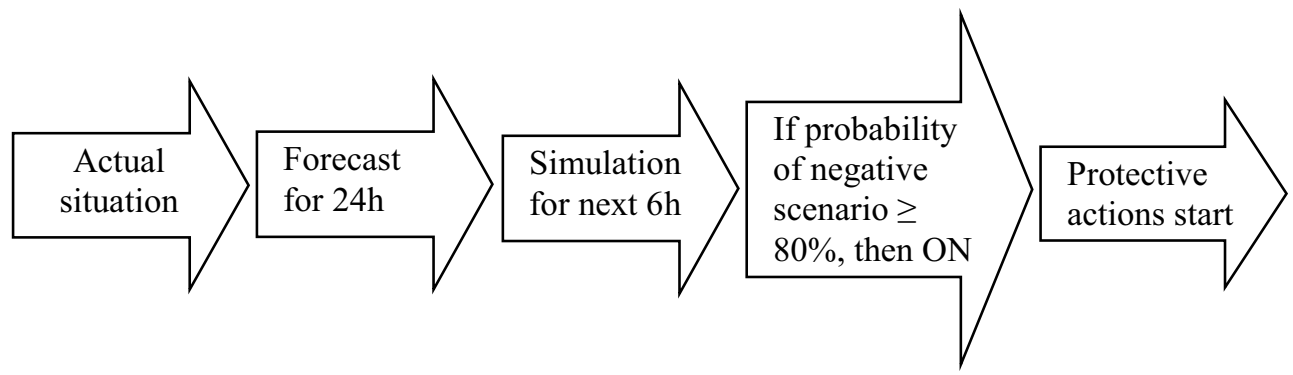

Fig. 2. Role of simulation in process of concreting in low temperature

On the building site, manager has to make a decision about concreting based on weather forecasting which is inaccurate and not stable. This is the reason why the condition on site and weather forecast must be updated. Figure 2 shows the consecutive steps in decision making system. Actual situation is concerned and confronts the forecast for $24 \mathrm{~h}$. In this time the delivery and additional task can be performed and the data from monitoring devices are still collected. However, changes that are difficult to predict may occur and therefore a systematic update must be carried out for both: monitored process and weather forecast. The simulation is performed every 6 hours (based on updating process of weather forecast). If the coefficient of risk of damage in concrete structure $\left(C_{f}\right)$ is higher than $80 \%$ then the protective action starts. This coefficient is calculated based on simulation according to the following formula:

$$
C_{f}=\frac{\sigma_{F}}{f_{t}}
$$

where, $\sigma_{\mathrm{F}}$ - freeze stress,

$\mathrm{f}_{\mathrm{t}}-$ tensile strength for maturing concrete.

The main idea of simulation implementation into construction site is presented at Figure 3. 


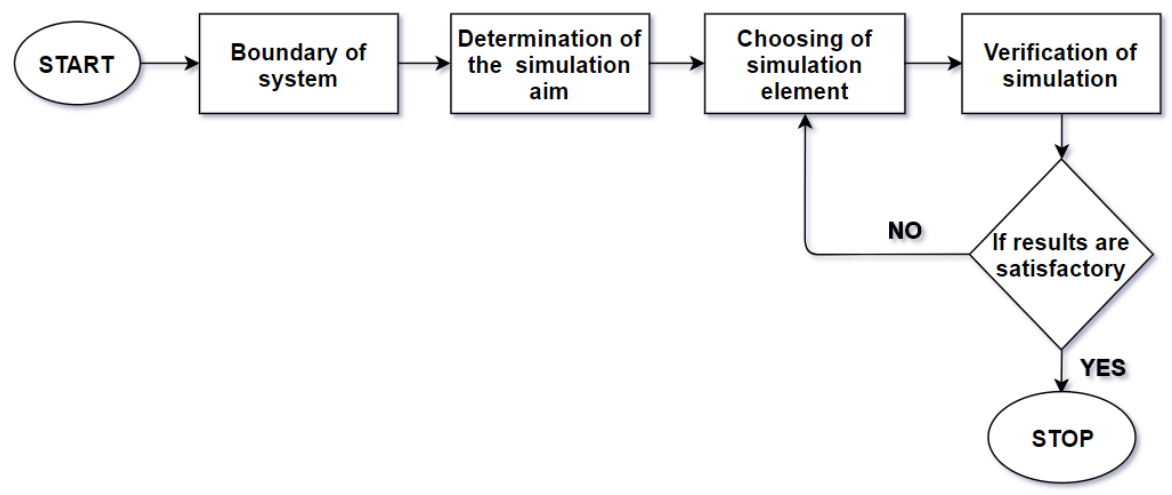

Fig. 3. Schema of simulation process for trigger of active flexibility option

Nowadays there are plenty of simulation software which usage depends on analysed situation. In construction industry are two main groups of simulations. First group refer to designing and simulate phenomena inside elements of construction structure, their compressive and tensile strength, force distribution, and durability over designed time. Examples of software used in this kind of simulation are: Abaqus, HACON and SolidWorks. BIM technology gives possibility to simulate the construction elements exactly from the design documentation, with all enhancements [14]. Dimyadi et al. [13] describe the usage of BIM technology to support simulation of compliant building evacuation.

The second group of software is concerned simulation of the delivery of construction product like ready-mix concrete or works which duration has enormous impact on schedule such as earthwork. The most popular software used in concrete delivery process simulation is MicroCyclone. This type of software allows to choose the number of concrete mixer trucks, reduce the rental costs of trucks as well as maximizing the efficiency of concrete work by eliminating mixer trucks' queuing and downtime [15]. The usage of simulation software in practice will be presented in the following case study.

\section{Case study}

Presented case study is based on concreting of sealed slab in local petrol station. The thickness of this slab $(0.18 \mathrm{~m})$ is relatively small in relation to the width $(7 \mathrm{~m})$ and length $(10 \mathrm{~m})$. The phenomena in sealed slab during maturing of fresh concrete simulation was performed in HACON program.

The HACON basis on FEM analysis. The theoretical aspect of FEM is based on temperature correlation between finite elements. The final element method is a numerical approach of solving differential equations describing physical problems. The program solve this equation by a finite element formulation and is estimating by a weak formulation with usage of Galerkin method. Simulation process is based on experiments performed in semiadiabatic conditions (self-heating of concrete) and isothermal conditions (dynamics of increasing the strength of concrete depending on the temperature) in lab. The results from HACON program simulation are presented at Figure 4. 


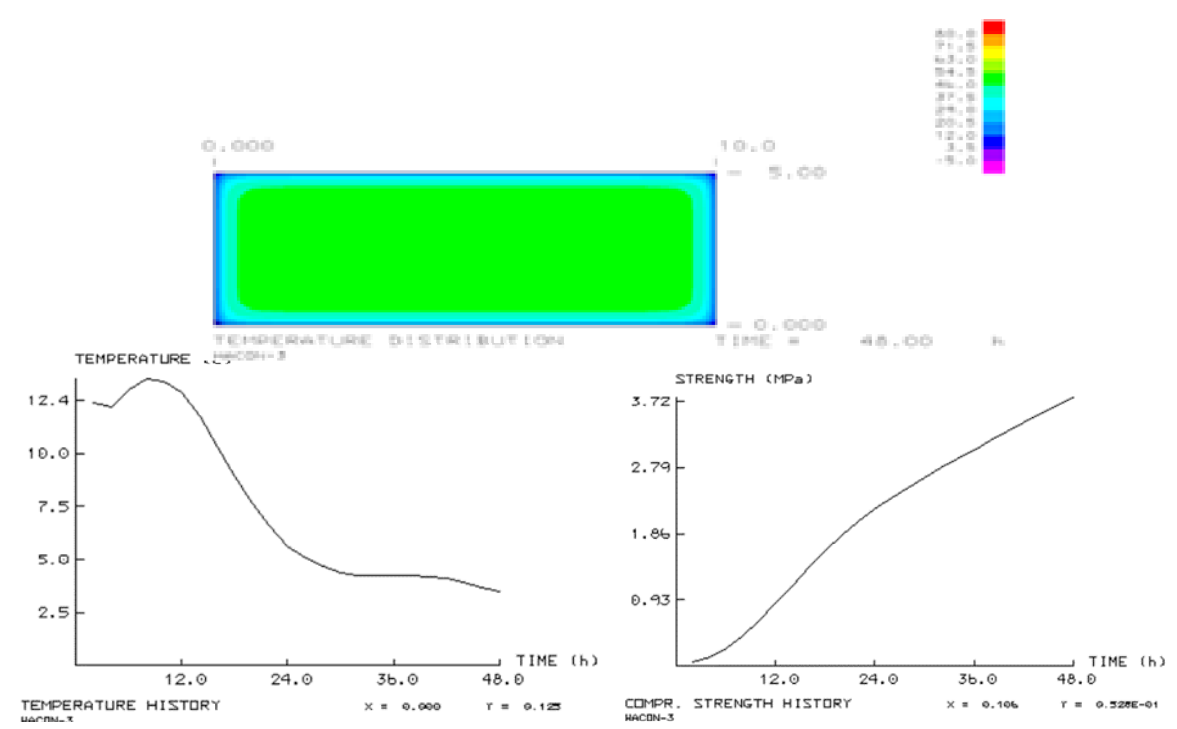

Fig. 4. The result from program HACON- heat and strength distribution in concrete slab

The results from simulation shows that compressive strength after 48 with changes in forecast temperature (with frequent updates), and without this changes, differ and in the traditional situation the unexpected low temperature cause an inhibition in compressive strength growth. Predicted value of compressive strength according to forecasting temperature were planned on $9.52 \mathrm{MPa}$ after $48 \mathrm{~h}$ but in real case the compressive strength was confirmed at $3.8 \mathrm{MPa}$.

The traditional approach assumes the weather forecast, monitoring the temperature in concrete but rare simulation process (for next $24 \mathrm{~h}$ or $48 \mathrm{~h}$ ). The changes in temperature within this period of time can be visible and significant, especially in winter condition at night. This is the reason of introducing the new solution with frequent simulation and flexible option. Simulation based on weather forecast and monitoring is frequent (is performed every $6 \mathrm{~h}$ ) what allow to observe the fall in temperature. If the temperature in concrete drops than the additional flexible actions can be done.

\section{Conclusions}

All theoretical approaches as well as case study discoursed above allows to draw the following conclusions:

1. Traditional approach (no monitoring of construction operation in progress, no simulation of phenomena in concrete element, no updating of weather forecast) for concreting at low temperature is very risky

2. Simulation plays significant role in decision-making process and considers the active simulation option

3. The FEM is more and more popular and commonly used in construction industry

4. Due to usage a BIM technology as well as simulation, processes on building site can be planed and managed more efficiently (what cause smaller wastes of money and time in comparison with traditional approach) 
5. The simulation allow to observe the impact of the real changes in weather on heat distribution in concrete slab and allow to trigger protective flexible action.

The further studies can consider the influence of using flexible approach in concreting process depending on changes in weather forecast and more frequent updating actions.

\section{Acknowledges}

This work was supported by Institute of Structural Engineering Poznan University of Technology.

\section{References}

1. Ballesteros-Pérez, P.; Smith, S. T.; Lloyd-Papworth, J. G.; Cooke, P. Incorporating the effect of weather in construction scheduling and management with sine wave curves: application in the United Kingdom. Constr. Manag. Econ., 85, 1-17, (2018) doi:10.1080/01446193.2018.1478109.

2. Ballesteros-Pérez, P.; Rojas-Céspedes, Y. A.; Hughes, W.; Kabiri, S.; Pellicer, E.; Mora-Melià, D.; del Campo-Hitschfeld, M. L. Weather-wise: A weather-aware planning tool for improving construction productivity and dealing with claims. Autom. Constr., 84, 81-95, (2017) doi:10.1016/j.autcon.2017.08.022.

3. M. Pawelska-Mazur Warunki betonownia w obniżonych temperaturach na przykładzie Pomorza. Przeglad Bud., R. 82, nr, 25-29, (2011).

4. Andrzejczak, K.; Karlowski, A.; Paslawski, J. O. Flexible management for concrete curing at low temperature based on learning from cases. 34th Int. Symp. Autom. Robot. Constr. ISARC 2017, 112-119, (2017), doi:10.22260/ISARC2017/0015.

5. Pasławski, J. Elastyczność w zarządzaniu realizacja procesów budowlanych; Wydawnictwo Politechniki Poznańskiej, (Poznań 2009)

6. Maria, A. Proceedings of the 1997 Winter Simulation Conference., 7-13, (1997).

7. AbouRizk, S.; Halpin, D.; Mohamed, Y.; Hermann, U. Research in Modeling and Simulation for Improving Construction Engineering Operations. J. Constr. Eng. Manag., 137, 843-852, (2011) doi:10.1061/(ASCE)CO.1943-7862.0000288.

8. Daniel W. Halpin, L. S. R. Planning and Analysis of Construction Operations; John Wiley \& Sons, (1992); ISBN 0-471-55510-X.

9. $\quad$ Grigoryev, I. AnyLogic 8 in Three Days. (2018), doi:978 9241502153.

10. Dawood, N.; Sriprasert, E.; Mallasi, Z.; Hobbs, B. Development of an integrated information resource base for $4 \mathrm{D} / \mathrm{VR}$ construction processes simulation. Autom. Constr., 12, 123-131, (2003), doi:10.1016/S0926-5805(02)00045-6.

11. Ioannou, P. G.; Martinez, J. C. Simulation of complex construction processes. In Proceedings of the 28th conference on Winter simulation - WSC '96; ACM Press: New York, New York, USA, 1321-1328, (1996).

12. Lu, M.; Wong, L. C. Comparing promodel and sdesa in modeling construciton operations. Proc. - Winter Simul. Conf., 1524-1532, (2005), doi:10.1109/WSC.2005.1574420.

13. Kapliński, O. Modeling Construction Processes: a Review of Research and Disserations at the Poznan University of Technology. Civ. Environ. Eng. Reports, $85-105,(2005)$

14. Dimyadi, J.; Amor, R.; Spearpoint, M.; Compliant, C.; Practice, D. Using BIM to 
Support Simulation of Compliant Building Evacuation. Proc. 11th Eur. Conf. Prod. Process Model. (ECPPM 2016), 511-518, (2016).

15. Dziadosz, A.; Konczak, A. Decision-making process in the construction industry. Arch. Civ. Eng., 62, 111-126, (2016). 